\title{
Measuring and predicting mental health literacy for depression
}

\author{
Emily J. Swannell and Mark R. McDermott* \\ School of Psychology, University of East London, London, UK \\ (Received 21 August 2015; final version received 25 August 2015)
}

\begin{abstract}
This study investigated if mental health literacy for depression is a multidimensional construct, and sought to identify its components and to construct empirically derived questionnaire subscales. Following a literature review, items were generated to produce five conceptual subscales. These were administered to 228 respondents (136 females, 92 males), along with others measuring psychological constructs of theoretical relevance, specifically assessing: emotional intelligence, mindfulness, interdependence and independence, rebelliousness, and depressive symptomatology. Principal components analysis of the 38-item pool confirmed a 3-factor solution: (1) Knowledge and belief in psychological strategies for reducing depression, (2) Ability to recognise depression, and (3) Knowledge and beliefs in positive self-care habits for reducing depression. These components comprise the Public Understanding of Depression Questionnaire (PUDQ). Interdependence, emotional intelligence, sex of respondent and previous history of medication for mental health difficulties were found to be independently predictive of scores on the PUDQ subscales, supporting their construct validity, with Cronbach's Alpha coefficients indicating their internal reliability. The PUDQ is a novel multidimensional tool which can be used in the delivery and assessment of strategies for promoting the understanding of depression amongst at-risk groups.
\end{abstract}

Keywords: Depression; public understanding; literacy; mental health

\section{Introduction}

Seventeen per cent of adults in the UK are currently experiencing a mental health disorder, with the majority $16 \%$ being diagnosed with a common mental health disorder such as anxiety or depression (McManus, Meltzer, Brugha, Bettington \& Jenkins, 2009). The indirect cost of depression, the most prevalent disorder in the UK, is $£ 8$ billion per annum (National Institute for Health \& Care Excellence, 2009). Lord Layard's 2006 national programme, 'Improving Access to Psychological Therapies' (IAPT) has led to the widespread commissioning of talking therapies for depression in primary care mental health care settings throughout the UK. Recent audits of these programmes have shown that out of the estimated 6.1 million people with anxiety and depression in the UK, only $4.7 \%$ of these accessed IAPT services in the second quarter of 2014 (Community and Mental Health Team, 2015), while a quarter of 14-24-yearolds were found not able to recognise depression in a case vignette (Loureiro et al., 2013). This suggests that many people with affective disorder are still to be reached and helped. In a study by Furnham, Cook, Martin, and Batey (2011), a fifth of young people (aged 18-23 years) responded that they had not ever heard of depressive

Corresponding author. Email: m.r.mcdermott@uel.ac.uk 
disorder, suggesting that identifying depression is problematic for non-mental health professionals. That depression is still the 'common cold of psychopathology' (Seligman, 1973) coupled with extensive non-recognition of the disorder both illustrate that there is a real and specific need to investigate how mental health literacy (MHL) for depression might be assessed and improved in the general population.

Jorm (2012) argues for the promotion of MHL so that public services are aligned with people's knowledge and help-seeking behaviours and is used to drive the development of targeted health promotion and prevention programmes. MHL has been defined as 'The knowledge and beliefs about mental health disorders which aid their recognition, management or prevention' (Jorm et al., 1997 p. 182). To effectively incorporate MHL into the public health agenda, Jorm (2012) argues that five facets need to be addressed: knowledge of how to prevent mental health disorders; recognition of when a disorder is developing; knowledge of help-seeking behaviours and treatments available; knowledge of effective self-help strategies; and finally, first aid skills to help others affected by a mental health disorder. O'Connor, Casey, and Clough (2014) argue these facets of MHL are addressed variously by studies, with few incorporating all of them.

\section{MHL, support seeking and depression}

People do not access support for depression for a variety of reasons, including, for example, the associated stigma (Coppens et al., 2013). Failure to identify and correctly label symptoms of depression are also known to impact on seeking professional support (Wright, Jorm, Harris, \& McGorry, 2007). A systematic review of studies on barriers to seeking support for all mental health disorders has confirmed that the ability to selfidentify a disorder impacts on seeking professional support (Gulliver, Griffiths, Christensen, \& Brewer, 2010). However, a further more recent review by Gulliver, Griffiths, Christensen, and Brewer (2012) concluded that MHL interventions whilst able to improve help-seeking attitudes cannot be clearly seen to have such effects on behaviours. Further, public perceptions of how helpful professional support for depression will be has been shown to impede help-seeking behaviour (Jorm et al., 1997). Research has also shown that the perceived effectiveness of treatment differs depending on the disorder, with mental health professionals being seen as more helpful when treating schizophrenia than depression (Angermeyer, Matschinger, \& Riedel-Heller, 1999), with Van Voorhees et al. (2006) also finding that a lack of confidence in treatments for depression influences treatment seeking among young adults. Another reason why people may not access support for depression is that they are differentially encouraged to do so by others: Jorm, Blewitt, Griffiths, Kitchener, and Parslow (2005) found that most respondents in their study would encourage others to seek professional help, listen to and support the individual if in distress, and that this was particularly so for women respondents.

\section{MHL for depression measures and interventions}

Despite the MHL framework offered by Jorm (2012), O' Connor, Martin, Weeks, and Ong's (2014) review of 13 studies reporting MHL measures observed that none assessed knowledge of how to seek information or knowledge of self-treatment, concluding that there are 'substantial limitations in current ability to measure MHL' (p. 1360). An analysis of MHL for depression measures reveals similar limitations. Jorm et al. (1997) solicited indices of MHL for depression using a vignette-based 
approach in which participants were asked what they thought was wrong with the person depicted and how they could be helped, and thereafter interviewed them about other aspects of MHL for depression. Likewise, Reavley, Morgan, and Jorm (2014), in a large study incorporating health professionals as expert raters and over 6000 respondents, report using responses to vignettes to construct MHL scale scores which they found to be related to prior exposure to mental disorders and to age, gender and education. Such a method, however, is relatively time-costly to deliver at a population level, unlike questionnaire measures. Dunn, Goldney, Grande, and Taylor (2009) and Goldney, Dunn, Grande, Crabb, and Taylor (2009) have reported creating an algorithm, using vignettes with which to measure depression-related MHL. Though able to demonstrate changes over time in depression-related MHL, the allocated scores addressed factors articulated by the participant's lay beliefs about the causes of depression rather than by an understanding derived from the available evidence base. Similarly, Loureiro et al. (2013) use a vignette as a starting-point about which were asked a series of questions to elicit scores on the five facets of MHL as specified by Jorm (2012). Within these, however, it is notable that the role of psychosocial variables as risk factors for depression is not specified systematically, and that the architecture of depression-related MHL as a five-part scheme is adopted without empirically testing this assumption. Determining the structure of depression-related MHL beliefs and deriving a measure that reflects this structure is important for developing interventions that enhance such literacy and for evaluating their efficacy. Griffiths, Christensen, Jorm, Evans, and Groves (2004) found that enhancing depression-related MHL through a web-based intervention has a positive effect on stigmatising attitudes towards depression amongst those with high levels of such affect. Similarly important is the identification of factors that predict depression-related MHL.

\section{Predicting MHL for depression}

Age has been shown to predict the ability to identify depression and where to seek support, with Farrer, Leach, Griffiths, Christensen, and Jorm (2008) finding that older adults (70+ years) were poorer at identifying depression than younger adults (18-24year-olds). Jorm and Wright (2007) further found that young adults (15-25-years-old) were more likely to seek support from their peers instead of accessing professional support. For gender, Swami (2012) found women to be better than men at identifying depression in a vignette featuring a man and participants are more likely to see a vignette featuring a woman as having depression. Likewise, Furnham et al. (2011) found that women had higher MHL for depression in a sample of UK college students. Women have also been identified as having a more positive attitude then men toward help-seeking behaviour (Ang, Lim, \& Tan, 2004; Mackenzie, Gekoski, \& Knox, 2006; Masuda, Suzumura, Beauchamp, Howells, \& Clay, 2005). It has also been shown that predictors of favourable attitudes to seeking treatment reside in participants who have sought support in the past (Cash, Kehr, \& Salzbach, 1978; Masuda et al., 2005). Also, individual personality factors have been used to predict MHL for depression. Swami, Papanicolaou, and Furnham (2011) examined the British public's familiarity with mental health disorders and the relationship between the 'Big 5' personality constructs and intelligence: Greater accuracy in identifying mental health disorders including depression was shown to be significantly associated with higher rates of self-rated intelligence and psychiatric scepticism. Higher trait emotional intelligence (TEI) was found by Furnham et al. (2011) to predict higher MHL, with participants more able to define 
different mental health disorders including depression if they had higher TEI. Similarly, Rickwood, Deane, Wilson, and Ciarrochi (2005) found that university students who felt less skilled at managing emotions were less willing to seek help (from professionals, family or friends) for suicidal ideation and personal emotional problems, compared with those with higher emotional competence.

Mindfulness has also been linked to attitudes to seeking support and symptoms of depression (Oluyinka, 2011). High mindfulness scores in Nigerian students were found to correlate with better attitudes towards seeking professional psychological help. Studies have also shown that interdependence and being independent are linked to recognition of mental health difficulties and seeking support. In this vein, Yeh (2002) found that there is a relationship between interdependence and positive beliefs about seeking help from a counsellor or therapist. Tata and Leong (1994) similarly found that participants who were self-reliant and independent tended not to seek professional psychological help.

Individual differences in resistance to internalising information about MHL for depression is another variable which is likely to be relevant in this context, with research by Klabbers et al. (2009) showing a link between rebelliousness and unhealthy behaviours in a large Dutch sample. Further, Albers and Biener (2002) have found that rebelliousness is linked to adolescent smoking and subsequent symptoms of depression, whilst McDermott (1987) found a significant relationship between proactive rebelliousness and scores on three subscales from the General Health Questionnaire (Goldberg \& Hillier, 1979), specifically for severe depression, somatic symptoms, and anxiety and insomnia. A potentially inverse relationship between rebelliousness and MHL is further suggested by the findings of Boddington and McDermott (2013) wherein proactive rebelliousness was found to be an independent predictor of resistance to persuasive messages which targeted a paradoxical health behaviour. Given the associations between rebelliousness, symptoms of depression and unhealthy behaviours, further examination of resistance in relation to MHL for depression is indicated.

\section{The current study}

The research above has relied in large part upon the use of vignettes to solicit levels of MHL and suggests that there is a need to broaden further our understanding of predictors of literacy for depression, despite developments in this area. In particular, Jorm's (2012) theorising implicates the need for the multidimensional measurement of MHL for depression, to empirically investigate the structure of depression-related MHL, and to assess thereby the correlates of such components. So, a study is reported here which sought to produce a new multidimensional self-report measure of MHL for depression and to identify psychological factors that independently predict scores on the emergent questionnaire components. In this way, it is anticipated that the results of this research will permit a more nuanced understanding of MHL beliefs, the incorporation of additional predictor variables into interventions and targeted policies to improve public MHL for depression.

In deriving this new measure and in light of investigations into mental healthrelated awareness and understanding, this study will address a number of hypotheses: firstly, it is proposed that the development of a MHL for depression questionnaire will identify multiple components, as suggested by Jorm (2012); secondly, participant's understanding of depression will be significantly positively correlated with selfmeasured symptoms of depression and previous treatment for mental health disorders; 
thirdly, participant's understanding and awareness of depression will be positively correlated with emotional intelligence (EI), mindfulness (MAAS), interdependence, and negatively correlated with rebelliousness; finally, women participants will have significantly higher levels of understanding of depression than men.

\section{Method}

\section{Participants}

The total sample of 228 participants consisted of 136 women and 92 men, with a mean age of 27.6 years $(\mathrm{SD}=9.8 ; \min .=18, \max .=64)$. Of these participants, the majority were full-time students (59\%), with the second largest group being full-time employed individuals $(n=76 ; 33 \%)$. Out of the 135 students, the majority were studying Psychology on taught undergraduate or postgraduate courses $(n=99)$. The sample was ethnically heterogeneous: $52 \%$ of participants self-designated as 'White British' $(n=119)$, $10.5 \%$ as 'White European', $11 \%$ a s 'Black British', 5.2\% as 'Asian British', $4 \% \mathrm{a}$ s 'Black African/Caribbean', $4 \%$ a s 'Bangladeshi British', $4 \%$ a s 'Indian British', $4 \%$ a s 'Pakistani British', with 5.3\% as 'other' ethnicities. An attempt was made to include only participants with a lay, non-professional understanding of mental health. Thus, only eight participants (4\%) employed by the NHS were included in the study.

\subsection{Materials}

Materials given to all participants consisted of a consent form, questionnaires and debriefing information, either as a hardcopy booklet or online via SurveyGizmoStudent. The questionnaire booklet consisted of seven sections, relating to separate questionnaires and the soliciting of demographic information.

The first section contained the author-generated 47-item Public Understanding of Depression Questionnaire (PUDQ). The PUDQ contained items generated in relation to conceptual themes derived from Jorm's (2012) MHL model. The items were presented in a randomised order to prevent response sets. The conceptual subscales were as follows: firstly, 'How to prevent mental health disorders', consisting of 10 questions with a seven-point Likert response scale, asking how helpful participants felt individual preventative strategies were for depression, an item being, for example, 'How helpful do you think are engaging in daily enjoyable activities (for example, socialising with friends and family) in preventing depression?'; the second theme was 'Recognition of when a disorder is developing', the subscale consisting of 11 questions framed in relation to DSM-IV-TR symptoms of depression (American Psychiatric Association, 2000), with a seven-point response Likert scale, asking how much people believe that the symptoms were a sign of depression, an item being, for example, 'To what extent are appetite changes a sign of depression?'; the third conceptual subscale consisted of nine questions addressing 'Knowledge of effective self-help strategies', (guidance about selfhelp strategies were found from NHS 'choices' website and MIND website), an example being: 'To what extent does regular exercise help reduce symptoms of low mood?'; the fourth theoretical conceptual subscale was about 'First aid skills to help others' and consisted of six questions assessing a respondent's knowledge about skills that could help others who may have symptoms of depression, guidance for the content of this section coming from UK National Health Service (NHS) and MIND websites, an example item being, 'If you identified a close friend as feeling depressed would it be a 
good idea to advise them to visit their doctors surgery?'; and, lastly the fifth conceptual subscale addressed 'Knowledge of help seeking behaviours and treatments available' and consisted of 10 items, with guidance for the content of these coming from the NHS and the UK National Institute of Clinical Excellence websites, participants being asked to select one correct answer from a list, for example, 'What does CBT stand for? Counselling Based Treatments, Childhood Behaviour Therapies, Cognitive Behaviour Therapy, Compulsive Behaviour Treatment, or Couples Based Therapy'.

The second section of the questionnaire booklet consisted of the psychometrically reliable and valid Self-Construal Scale as developed and updated by Singelis (1994), measuring the strength of an individual's self-perceptions of their interdependence with and independence of others. Interdependence therein is about the extent to which one sees oneself as part of a collective in terms of feelings, actions and values, whilst independence is about viewing oneself as separate from these. The third section of the questionnaire contained the nine-item Patient Health Questionnaire (PHQ-9) by Kroenke, Spitzer, and Williams (2001), a self-report measure of the severity of DSMIV symptoms of depression. This questionnaire has been shown to have good validity in two meta-analyses (Gilbody, Richards, Brealey, \& Hewitt, 2007; Wittkampf, Naeije, Schene, Huyser, \& van Weert, 2007). The fourth section of the questionnaire booklet contained the Schutte Emotional Intelligence Scale (Schutte et al., 1998). The fifth section of the booklet contained the Mindful Attention Awareness Scale by Brown and Ryan (2003), with MacKillop and Anderson (2007) showing it to be a valid measure of mindfulness. The sixth section contained the Social Reactivity Scale (McDermott \& Apter, 1988) which measures proactive and reactive rebelliousness, its validity and reliability having been demonstrated by Klabbers et al. (2009). The seventh and last section of the questionnaire booklet contained items soliciting information about respondent's demographic characteristics (age, ethnicity, gender and occupation).

\section{Procedure}

Participants were recruited either face to face $(n=48)$ or online $(n=180)$. Potential participants first were presented a letter of introduction which outlined the general purpose of the study as one examining the public understanding of mental health. They were then asked to consent to taking part having been informed they could withdraw from the study without consequence at any point. Online recruitment of participants utilised 'snowballing' to maximise respondent numbers, wherein participants who were emailed to take part in the study, were also asked to pass on the study web-link to other people they knew. Face-to-face recruitment of participants took place opportunistically at a London university campus.

\section{Results}

The strategy employed to analyse the data was firstly to carry out item analyses on the author-devised PUDQ item pool in order to examine its underlying dimensionality and to empirically derive subscales, thereby testing the original conceptual scheme used to compile the measure. Then, we explore relationships between the independent variables in the study with the three empirically derived factors of the PUDQ. In the first instance, this was done bivariately, that is between each independent variable and each dependent variable, without controlling for the interrelationships amongst independent variables. This is through use of Pearson Product moment correlations for IVs that 
produced interval data. For those producing nominal data, independent $t$-tests on these variables (for example, gender) were conducted to identify differences between respondents on the scores for the newly derived PUDQ factors. Thereafter, in the third stage of the analysis, for each of the PUDQ factors, two-stage multivariate correlational analyses in the form of multiple regressions were performed with the independent predictor variables that had been found to be significant correlates in the preceding bivariate analyses or as significant discriminators in the $t$-tests. This third stage of the analysis establishes which of the independent variables independently of each other predict scores on the PUDQ subscales. Two-stage regressions were used so that in the first instance we could establish which demographic factors independently predict scores on the PUDQ, and thereafter to investigate whether the addition of psychological variables further increased the predictive power of the emergent model.

The percentage of missing values in the data-set was minimal at $.16 \%$. However, missing values were replaced with computed indices of central tendency (median or modal values, depending upon the categorical/non-categorical nature of a variable). The small percentage of missing data was primarily attributable to the majority of participants completing the questionnaire online wherein SurveyGizmo does not allow respondents to continue through a questionnaire if an answer to an item has not been given.

\section{Item analysis of the PUDQ}

Principal components analyses (PCA) were conducted on the PUDQ to detect empirically derived sub-components. Firstly, a scree analysis (Cattell, 1966) was conducted on 38 items of the 47 in the PUDQ to determine how many factors are identifiable within the data. In this initial analysis, the fifth conceptual subscale 'Knowledge of help seeking behaviours and treatments available' was not included as the data was by definition categorical and binary in kind. The scree analysis for the remaining 38 items indicated that three components could be extracted, given three components are clearly visible before the start of the 'elbow' in the scree plot by the three 'jumps' down to the top of the scree. Therefore, secondly, a further PCA was carried out in which a three-factor solution was specified, with varimax rotation to ensure the production of orthogonal factors which maximise the amount of unique variance accounted for by each factor. These three components were found to respectively explain 24.7, 8.64 and $5.51 \%$ of the variance in the item correlation matrix, totalling $38.85 \%$. Other PCA solutions were checked: a two-factor solution explained less total variance in the correlation matrix (33\%); though four-factor and five-factor solutions accounted for additional total variance ( 43 and $47 \%$, respectively), these solutions were not interpretable, with either numerous items loading substantively on more than one factor, or the additional factors containing insufficient numbers of high loading items to comprise a subscale. Thereby, a three-factor PCA provided a best-fit solution, albeit that there remains unexplained variance in the correlation matrix. Accordingly, items which loaded on only one factor above .4 were selected to be incorporated into the three emergent factors subscales (see Table 1). Out of the 38 items, 31 items loaded in this way onto the three factors. Seven items were excluded as they either did not load above .4 , or did not load exclusively on any one factor. After examining the content of the items loading onto each of the three components, factor one was labelled 'Knowledge and belief in psychological strategies for reducing depression', factor two was labelled 'Ability to recognise depression', and factor three was labelled 'Knowledge and positive self -care habits for reducing depression'. 
Table 1. Item loadings from the principal components analysis

\begin{tabular}{|c|c|c|c|c|}
\hline Question & & $\begin{array}{c}\text { Factor } \\
1\end{array}$ & $\begin{array}{c}\text { Factor } \\
2\end{array}$ & $\begin{array}{c}\text { Factor } \\
3\end{array}$ \\
\hline \multicolumn{5}{|c|}{ Factor 1 'Knowledge and belief in psychological strategies for reducing depression' } \\
\hline 1 & $\begin{array}{l}\text { If you identified a loved one as feeling in a low mood as } \\
\text { a result of a problem, would it be good practise to help } \\
\text { them find a solution to that problem? (26) }\end{array}$ & .75 & .05 & .10 \\
\hline 2 & $\begin{array}{l}\text { If you identified someone at work as feeling in a low } \\
\text { mood would it be a good idea to encourage them to } \\
\text { spend more recreational time with other people, instead of } \\
\text { being on their own? (22) }\end{array}$ & .63 & .09 & .21 \\
\hline 3 & $\begin{array}{l}\text { If you identified a loved one as feeling in a low mood } \\
\text { would it be good practise to listen nonjudgmentally to } \\
\text { how that person is feeling? (30) }\end{array}$ & .62 & .12 & .19 \\
\hline 4 & $\begin{array}{l}\text { If you identified someone at work as being depressed, } \\
\text { would it be a good idea to encourage them to talk to } \\
\text { someone they are close to about how they feel? (15) }\end{array}$ & .60 & .27 & -.01 \\
\hline 5 & $\begin{array}{l}\text { How helpful do you think talking through your problems } \\
\text { with someone who is supportive is for preventing } \\
\text { depression? (40) }\end{array}$ & .60 & .17 & .31 \\
\hline 6 & $\begin{array}{l}\text { To what extent can reducing negative thoughts help lift } \\
\text { low mood? ( } 31)\end{array}$ & .56 & .07 & .31 \\
\hline 7 & $\begin{array}{l}\text { How helpful do you think having a close confiding } \\
\text { relationship would be for preventing depression? (18) }\end{array}$ & .55 & -.02 & .21 \\
\hline 8 & $\begin{array}{l}\text { To what extent are frequent thoughts over a two week } \\
\text { period of wanting to harm yourself a sign of depression? } \\
\text { (47) }\end{array}$ & .55 & .14 & .04 \\
\hline 9 & $\begin{array}{l}\text { How helpful do you think reducing daily stress is for } \\
\text { preventing depression? (36) }\end{array}$ & .54 & .02 & .33 \\
\hline 10 & $\begin{array}{l}\text { To what extent is increasing the frequency of pleasurable } \\
\text { activities a remedy for low mood? (8) }\end{array}$ & .50 & -.02 & .25 \\
\hline 11 & $\begin{array}{l}\text { How helpful do you think are engaging in daily enjoyable } \\
\text { activities (for example, socialising with friends and } \\
\text { family) in preventing depression? (1) }\end{array}$ & .48 & .01 & .09 \\
\hline 12 & $\begin{array}{l}\text { To what extent is talking about problems helpful for } \\
\text { people who have low mood? (4) }\end{array}$ & .41 & .12 & .22 \\
\hline \multicolumn{5}{|c|}{ Factor 2 'Ability to recognise depression' } \\
\hline 1 & $\begin{array}{l}\text { To what extent is lack of concentration a sign of } \\
\text { depression? (45) }\end{array}$ & .07 & .74 & .22 \\
\hline 2 & $\begin{array}{l}\text { To what extent is sleeping too much a sign of depression? } \\
\text { (16) }\end{array}$ & .15 & .67 & .06 \\
\hline 3 & $\begin{array}{l}\text { To what extent is little interest in doing pleasurable } \\
\text { activities most of the time a sign of depression? (12) }\end{array}$ & .17 & .64 & .11 \\
\hline 4 & $\begin{array}{l}\text { To what extent are appetite changes a sign of depression? } \\
\text { (13) }\end{array}$ & .06 & .63 & .15 \\
\hline 5 & $\begin{array}{l}\text { To what extent is speaking or moving slowly a sign of } \\
\text { depression? (33) }\end{array}$ & -.02 & .63 & .25 \\
\hline 6 & $\begin{array}{l}\text { To what extent is loss of energy a sign of depression? } \\
\text { (37) }\end{array}$ & .08 & .62 & .28 \\
\hline 7 & $\begin{array}{l}\text { To what extent is sleeping too little a sign of depression? } \\
\text { (23) }\end{array}$ & .05 & .59 & .04 \\
\hline 8 & $\begin{array}{l}\text { To what extent is appearing restless a sign of depression? } \\
\text { (27) }\end{array}$ & .03 & .59 & .18 \\
\hline 9 & To what extent is feeling guilty a sign of depression (41) & .09 & .56 & .22 \\
\hline
\end{tabular}




\begin{tabular}{|c|c|c|c|c|}
\hline Question & & $\begin{array}{c}\text { Factor } \\
1\end{array}$ & $\begin{array}{l}\text { Factor } \\
2\end{array}$ & $\begin{array}{l}\text { Factor } \\
3\end{array}$ \\
\hline 10 & $\begin{array}{l}\text { To what extent is feeling down or sad most of the time } \\
\text { over a two week period a sign of depression? (2) }\end{array}$ & .11 & .52 & -.06 \\
\hline \multicolumn{5}{|c|}{ Factor 3 'Knowledge and beliefs in positive self-care habits for reducing depression' } \\
\hline 1 & $\begin{array}{l}\text { How helpful do you think eating a healthy diet is for } \\
\text { preventing depression? (32) }\end{array}$ & .12 & .11 & .78 \\
\hline 2 & $\begin{array}{l}\text { To what extent does adopting a healthy diet help alleviate } \\
\text { low mood? }(25)\end{array}$ & .16 & -.01 & .76 \\
\hline 3 & $\begin{array}{l}\text { To what extent does regular exercise help reduce } \\
\text { symptoms of low mood? ( } 35)\end{array}$ & .29 & .12 & .62 \\
\hline 4 & $\begin{array}{l}\text { How helpful is doing } 30 \text { minutes of moderate exercise a } \\
\text { day (for example, a brisk walk) for preventing } \\
\text { depression? (44) }\end{array}$ & .32 & .13 & .60 \\
\hline 5 & $\begin{array}{l}\text { To what extent is good regular sleep effective for } \\
\text { remedying low mood? (39) }\end{array}$ & .36 & .25 & 54 \\
\hline 6 & $\begin{array}{l}\text { To what extent are relaxation techniques effective for } \\
\text { treating low mood? (19) }\end{array}$ & .30 & .04 & .54 \\
\hline 7 & $\begin{array}{l}\text { To what extent is reading a self-help booklet on } \\
\text { depression helpful for lifting low mood (14) }\end{array}$ & -.03 & .17 & 48 \\
\hline 8 & $\begin{array}{l}\text { How helpful do you think setting achievable goals (for } \\
\text { example, learning a new hobby) is for preventing } \\
\text { depression? (28) }\end{array}$ & .30 & .20 & .45 \\
\hline 9 & $\begin{array}{l}\text { To what extent does reducing alcohol consumption help to } \\
\text { lessen the symptoms of low mood? ( } 43 \text { ) }\end{array}$ & .21 & .22 & .41 \\
\hline
\end{tabular}

Note: Number in parentheses as in original item pool. Values in bold indicate items loading significantly (>.4) and discretely onto a factor.

The internal reliability of the three subscales derived from the principal components analysis was computed. The internal consistency was also computed for the fifth conceptual subscale 'Knowledge of help seeking behaviors and treatments available' which was not derived from the principal component analysis. Cronbach's $\alpha$ s for the three empirically derived factors were as follows: $\alpha=.85$ for factor 1 ; and, $\alpha=.83$ for factors 2 and 3. These alpha coefficients indicate highly acceptable levels of internal reliability. The fifth conceptual subscale had a low Cronbach's $\alpha$ s of .38 . Following this reliability analysis, it was decided that the fifth conceptual subscale 'Knowledge of help seeking behaviors and treatments available' would be removed and that further analysis would not be conducted on this conceptual component.

Descriptive statistical analysis for the three components was carried out. For the first factor, 'Knowledge and belief in psychological strategies for reducing depression', the mean score out of a possible 84 was $68.64(\mathrm{SD}=9.31$; $\min .=37$, $\max .=84)$. For the second factor, 'Ability to recognise depression', the mean score out of a possible 70 was $43.79(\mathrm{SD}=10.26$; $\min =11, \max .=68$,$) . For factor 3$, 'Knowledge and belief in positive self-care habits for reducing depression', a mean score of 46 out of a possible 63 was found $(\mathrm{SD}=8.19$; $\min .=25, \max .=63)$.

\subsection{Bivariate correlational analyses}

To explore relationships between the independent variables and the three empirically derived factors of the PUDQ, Pearson's ' $r$ ' bivariate correlations were computed (see Table 2). 
Scores on factor 1 'Knowledge and belief in psychological strategies for reducing depression' were found to be significantly and positively correlated with scores on Emotional Intelligence, the Singelis Measures of independence and interdependence, and MAAS Mindfulness, while also significantly and negatively correlated with those on the Patient Health Questionnaire and on the proactive rebellious subscale.

Scores on Factor 2, 'Ability to recognise depression', were found to be significantly and positively associated with those on the Singelis Measure of interdependence and Emotional Intelligence. Scores on factor 3, 'Knowledge and beliefs in positive self -care habits for reducing depression', were found to be significantly and positively related to those on the Singelis Measures of independence and interdependence, the measure of Emotional Intelligence and the MAAS Mindfulness measure. Further, both reactive rebelliousness and self- assessed symptoms of depression on the PHQ-9 were found to negatively correlate with scores on factor 3. Overall, these coefficients ranged from .13 to .36 , indicative of low levels of shared variance.

\section{t-tests on categorical independent variables}

Independent $t$-tests on categorical predictor variables (gender, whether working for the NHS, whether working for the NHS in mental health, and previous treatment and medication for mental health problems) were conducted to identify differences between respondents on the scores for the three PUDQ factors. Significant gender differences were found on factor 2, 'Ability to recognise depression', $(t=-2.78 \mathrm{df}=226, p<.03$, one-tailed), with women respondents (mean $=41.52, \mathrm{SD}=9.96$ ) being more able to correctly identify symptoms of depression than men $($ mean $=45.32, \mathrm{SD}=10.21)$. Significant differences were also found on this factor for previous history of psychotherapy for a mental health disorder $(t=-2.86, \mathrm{df}=225, p<.03$, one-tailed) and

Table 2. Bivariate Pearson's $r$ correlations (one-tailed) for the three factors of the PUDQ with the independent predictor variables

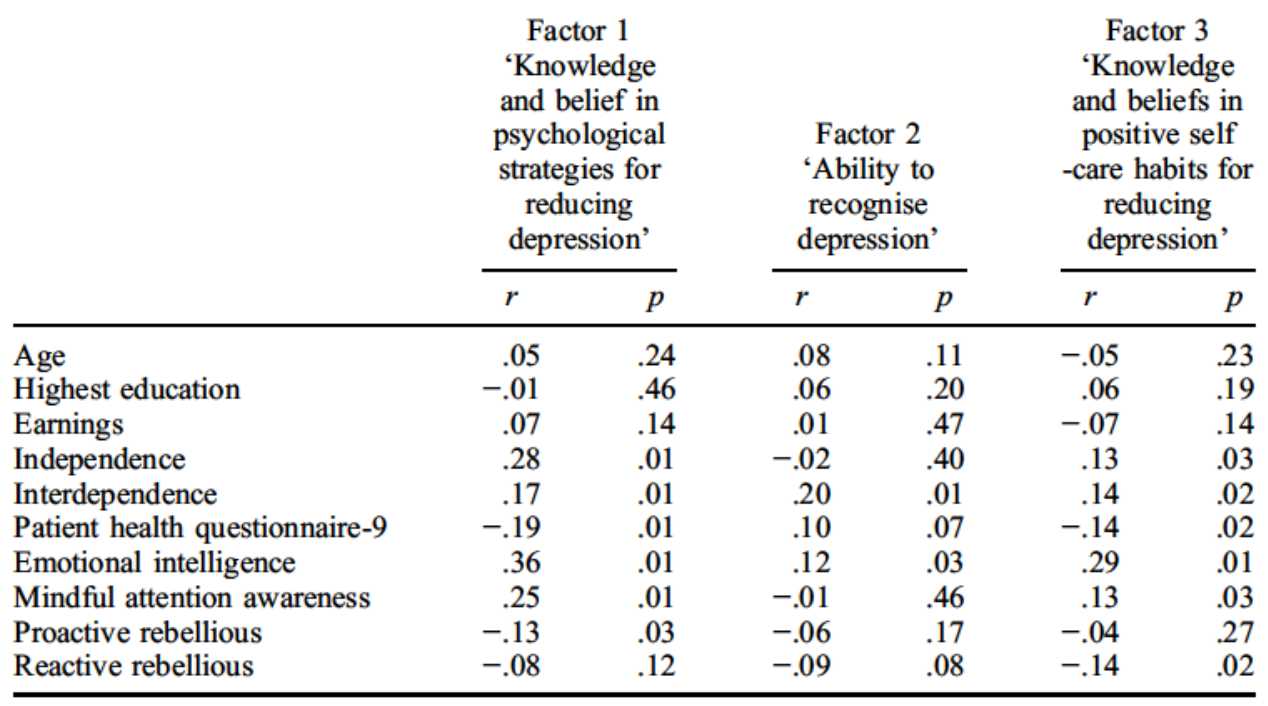

${ }^{*} p<.05 ;{ }^{* *} p<.01$. 
for previous medication taken for a mental health disorder $(t=-2.09, \mathrm{df}=225$, $p<.01$, one-tailed). Participants who had received psychotherapy in the past $($ mean $=48.11, \mathrm{SD}=10.24)$ and medication $($ mean $=49.32, \mathrm{SD}=10.92)$ were more able to identify symptoms of depression as compared to those who have not received past treatment or medication (mean $=42.96, \mathrm{SD}=10.08$ ) and (mean $=43.05$, $\mathrm{SD}=9.96$ ). Also, significant differences were found on factor 2 between those who work in the NHS and those who do not $(t=2.49, \mathrm{df}=225, p<.007$, one-tailed), and between those who work in the NHS in mental health service provision and those who do not $(t=2.21, \mathrm{df}=225, p<.014$, one tailed), with those in such roles scoring higher on 'Ability to recognise depression'. For scores on factor 3, 'Knowledge and beliefs in positive self -care habits for reducing depression', significant differences were found ( $t=-2.26, \mathrm{df}=225, p<.01$, one-tailed) between those who had received previous medication for a mental health disorder $($ mean $=41.75, \mathrm{SD}=8.91)$ and those who had not $($ mean $=45.45, \mathrm{SD}=7.99)$, with the latter having greater belief in the efficacy of self-help habits for depression. Comparisons of the 135 students, the majority of whom were studying psychology, with the 93 non-student respondents did not reveal the former to be more knowledgeable about MHL for depression on the three PUDQ components.

\section{Multivariate correlational analysis}

For each of the three empirically derived factors from the PUDQ, two-stage multiple regressions were performed with independent predictor variables which were found to be significant in the bivariate correlation analysis or in the $t$-test analysis (see Table 3 ).

Independent predictor variables for factor 1 'Knowledge and belief in psychological strategies for reducing depression' explained $17 \%$ of the variance in scores $\left(R^{2}=.17, F\right.$ $(8,216)=6.83, p<.01)$. Statistically significant independent correlations with this dependent variable were found for the Singelis Measure of interdependence $(\beta=.14$, $p<.03)$ and Emotional intelligence $(\beta=.20, p<.01)$.

For factor 2 'Ability to recognise depression', $16 \%$ of the variance was explained collectively by the independent predictor variables $\left(R^{2}=.16, F(9,216)=5.66\right.$, $p<.01$ ), with significant correlations found for the Singelis Measure of interdependence $(\beta=.23, p<.01)$ and for gender $(\beta=.20, p<.01)$, showing that women are significantly more able to recognise depression then men.

For factor 3, "Knowledge and beliefs in positive self -care habits for reducing depression', $10 \%$ of the variance was explained collectively by the independent variables $\left(R^{2}=.10, F(9,216)=3.85, p<.01\right)$ : Previous medication $(\beta=.13, p<.05)$ and emotional intelligence $(\beta=.29$. $p<.01)$ were found to be significant independent correlates of this dependent variable.

\section{Discussion}

\section{The main findings}

This study created a self-report measure, the PUDQ, and in so doing sought to assess which psychological and demographic factors best predict such understanding. The five conceptual components of MHL identified by Jorm (2012) were used as a starting point to develop the questionnaire. From factor analysis, three subscales were identifiable, all with high internal consistency. These three subscales comprise the new PUDQ, the 
Table 3. Regression analyses for the three factors of the PUDQ with independent predictor variables

\begin{tabular}{|c|c|c|c|c|c|}
\hline \multicolumn{2}{|c|}{ Model } & $\begin{array}{l}\text { Standardised } \\
\text { coefficients beta }\end{array}$ & $t$ & Sig. & $\begin{array}{l}\text { Adjusted } R \\
\text { square }\end{array}$ \\
\hline \multicolumn{6}{|c|}{ Factor 1 'Knowledge and belief in psychological strategies for reducing depression' } \\
\hline \multirow[t]{2}{*}{1.00} & Parental status & .12 & 1.77 & .08 & .04 \\
\hline & Occupation & .15 & 2.20 & .03 & \\
\hline \multirow[t]{8}{*}{2.00} & Parental status & .10 & 1.57 & .12 & .17 \\
\hline & Occupation & .12 & 1.71 & .09 & \\
\hline & Independence & .13 & 1.67 & .10 & \\
\hline & Interdependence & .14 & 2.16 & .03 & \\
\hline & Patient health questionaire-9 & -.01 & -.10 & .92 & \\
\hline & Emotional intelligence & .20 & 2.58 & .01 & \\
\hline & Mindful attention awareness & .10 & 1.39 & .17 & \\
\hline & Proactive rebellious & -.07 & -.93 & .36 & \\
\hline \multicolumn{6}{|c|}{ Factor 2 'Ability to recognise depression' } \\
\hline \multirow[t]{7}{*}{1.00} & Sex & .20 & 3.14 & .01 & .10 \\
\hline & Parental status & .08 & 1.24 & .22 & \\
\hline & Occupation & .12 & 1.74 & .08 & \\
\hline & Works for the NHS & -.04 & -.47 & .64 & \\
\hline & $\begin{array}{l}\text { Works for the NHS mental } \\
\text { health }\end{array}$ & -.09 & -1.06 & .29 & \\
\hline & $\begin{array}{l}\text { Previous psychotherapy } \\
\text { treatment }\end{array}$ & -.12 & -1.62 & .11 & \\
\hline & Previous medication treatment & -.10 & -1.34 & .18 & \\
\hline \multirow[t]{9}{*}{2.00} & Sex & .20 & 3.14 & .01 & .16 \\
\hline & Parental status & .07 & 1.14 & .26 & \\
\hline & Occupation & .13 & 1.92 & .06 & \\
\hline & Works for the NHS & .00 & -.02 & .98 & \\
\hline & $\begin{array}{l}\text { Works for the NHS mental } \\
\text { health }\end{array}$ & -.14 & -1.68 & .09 & \\
\hline & $\begin{array}{l}\text { Previous psychotherapy } \\
\text { treatment }\end{array}$ & -.11 & -1.49 & .14 & \\
\hline & Previous medication treatment & -.14 & -1.87 & .06 & \\
\hline & $\begin{array}{l}\text { Singelis measure of } \\
\text { interdependence }\end{array}$ & .23 & 3.58 & .01 & \\
\hline & Emotional intelligence & .07 & 1.15 & .25 & \\
\hline \multicolumn{6}{|c|}{ Factor 3 'Knowledge and beliefs in positive self-care habits for reducing depression' } \\
\hline \multirow[t]{3}{*}{1.00} & Parental status & .10 & 1.51 & .13 & .04 \\
\hline & Occupation & .10 & 1.52 & .13 & \\
\hline & Previous medication treatment & .16 & 2.48 & .01 & \\
\hline \multirow[t]{9}{*}{2.00} & Parental status & .09 & 1.40 & .16 & .10 \\
\hline & Occupation & .08 & 1.10 & .27 & \\
\hline & Previous medication treatment & .13 & 1.95 & .05 & \\
\hline & Interdependence & .07 & .98 & .33 & \\
\hline & Emotional intelligence & .29 & 3.54 & .01 & \\
\hline & Independence & -.06 & -.78 & .44 & \\
\hline & Patient health questionaire- 9 & .01 & .13 & .90 & \\
\hline & Mindful attention awareness & .03 & .43 & .67 & \\
\hline & Reactive rebellious & -.07 & -1.08 & .28 & \\
\hline
\end{tabular}

three components being: 'Knowledge and belief in psychological strategies for reducing depression'; 'Ability to recognise depression'; and 'Knowledge and belief in positive self-care habits for reducing depression'. The fifth conceptual subscale 'Knowledge of help seeking behaviours and treatments available' was not incorporated since it was not 
found to be internally reliable, whilst the item content was also too specific to local policy and so unlikely to be cross-culturally generalisable.

Following on from the creation of this three-dimensional questionnaire, psychological and demographic variables that were hypothesised to predict understanding of depression were tested. It was found that women had significantly higher scores than men on the 'Ability to recognise symptoms of depression' subscale. Multivariate analysis (regression) showed that scores on the emotional intelligence scale independently of all other variables predict scores on both the 'Knowledge and belief in psychological strategies for reducing depression' subscale and the 'Knowledge and belief in positive self-care habits for reducing depression', thereby partially supporting a study hypothesis and providing evidence for the construct validity of these two subscales. Notably, the $(N=135)$ students (most of whom were studying psychology) were not found to score higher on the PUDQ subscales than the $(N=93)$ non-student respondents.

Bivariate correlational analysis showed that both measures of independence and interdependence positively but weakly correlated with 'Knowledge and belief in psychological strategies for reducing depression'. Interdependence also positively correlated weakly with 'Ability to recognise depression'. 'Knowledge and belief in positive self-care habits for reducing depression' had a moderate correlation with interdependence, but a weak correlation with independence. Multivariate correlational analysis showed scores on interdependence to be a significant independent predictor of 'Knowledge and belief in psychological strategies for reducing depression' and also for 'Ability to recognise depression'.

'Knowledge and belief in positive self-care habits for reducing depression' was found in regression analysis to be negatively and significantly correlated with history of previous medication use, indicating that if an individual has received mental health medication in the past, they are less likely to see the benefits of self-care habits for reducing depression. This finding runs contrary to the direction of the hypothesis as stated.

Mindfulness (MAAS) also bivariately and positively correlated with 'Knowledge and belief in psychological strategies for reducing depression', and 'Knowledge and belief in positive self-care habits for reducing depression' but once subjected to multiple regression, Mindfulness (MAAS) was not found to be independently related with any subscale of the PUDQ.

There was a statistically significant weak correlation for scores on the Patient Health Questionnaire-9 measure of self-reported depression symptoms in bivariate analysis with 'Knowledge and belief in psychological strategies for reducing depression' and 'Knowledge and belief in positive self-care habits for reducing depression'. Regression analysis, however, did not confirm this as an independent association.

Bivariately, there were significant negative correlations between proactive rebelliousness and 'Knowledge and belief in psychological strategies for reducing depression' and with 'Knowledge and belief in positive self-care habits for reducing depression', neither of which were upheld as independent associations in regression analysis.

\section{Predictive and non-predictive variables}

Interestingly, three interrelated variables were found here to positively predict different aspects of MHL for depression: being a woman, seeing oneself as part of a collective (interdependence) and being emotionally intelligent. Conversely being a man, viewing 
oneself as not part of a collective, and scoring low on emotional intelligence were markers of less-developed MHL for depression, in addition to a history of prior medication use. We will consider each of these predictors in turn and their links to other relevant studies.

That women were more likely to recognise symptoms of depression than men supports the work of Swami (2012) who found women were better at identifying mental health disorders in vignettes than men, though not all MHL research has found this gender difference in detecting mental health disorders (Swami et al., 2011). This gender difference in depression literacy may account in part for the findings of the Psychiatric Morbidity Survey (McManus et al, 2009) which observed that men are diagnosed less often with common mental health disorders than women. Arguably, this inability to recognise the signs of depression allows disordered affect to become accentuated over time, with men being less likely to access support, contributing to twice as many men than women being in psychiatric hospitals under compulsory detainment and treatment (The Health \& Social Care Information Centre, 2008), with nearly three quarters of all suicides being amongst men (Hawton \& van Heeringen, 2009).

The construct of interdependence, which is about seeing oneself as part of a collective in terms of feelings, actions and values (Markus \& Kitayama, 1991), has been shown here to be associated with knowledge and belief in psychological strategies for reducing depression and the ability to detect depression. This result is consistent with other findings wherein interdependence has been found to co vary with positive beliefs about seeking support from a therapist (Yeh, 2002), with well-being (Lun, Kesebir, \& Oishi, 2008), and with lower levels of depression in teenagers (Lam, 2005). Interdependence may play a part in helping people recognise depression, and thereby in seeking support through talking to others. In this vein, Pevalin and Rose (2003) have found that men are less interdependent than women, men reporting lower frequency of contact with friends, lower attachment to their neighbourhoods and to be less frequent users of social support. Similarly, Anderson and Brownlie's (2011) 'Someone to Talk To' study examining the emotional lives of 2100 UK participants found that men were significantly more likely to feel that people in general talk too much about their feelings, were less likely to value the importance of such talk and more likely to find it difficult to converse about their emotions. Thereby men's low interdependence constitutes a psychological attribute which contributes to their lower levels of MHL for depression relative to that for women and may in part explain men's under-self-presentation in primary mental health service contexts.

That results here show those with greater emotional intelligence, like interdependence, to have greater awareness and belief in the efficacy of strategies for reducing depression (such as exercising, reducing alcohol and talking though their problems) is consistent with the work of Furnham et al. (2011), who found student participants with higher emotional intelligence were more able to define mental health disorders, while Rickwood et al. (2005) found that people who were less skilled at managing emotions were less willing to seek help for emotional problems. This is understandable when we consider that emotional intelligence can be defined as '... being able to recognise what we and other people feel, and finding ways to deal with those emotions' (Martins, Ramalho, \& Morin, 2010, p. 554). It is apparent that the ability to recognise the emotional states of others is an important concomitant of the ability to be mentally health literate for depression.

The fourth and last variable to be found here to be independently predictive of scores on the PUDQ was history of prior medication use, with that variable specifically 
predicting lower knowledge and beliefs in the efficacy of positive self-care habits for reducing depression. This finding is consistent with the notion that those who primarily rely on pharmacological intervention for the amelioration of their psychological difficulties, either as a cause or consequence of so doing, place comparatively little value on the utility of self-help strategies, this being consistent with Furnham and McDermott's (1994) findings that belief in the efficacy of self-reliance vs. seeking professional help (such as psychotropic medication) varies across different types of health difficulties.

Whilst having a developed sense of MHL for depression may benefit individuals in terms of promoting positive attitudes toward seeking timely professional support (Gulliver et al., 2012), it is recognised here that other variables are of predictive significance. It is well documented, for example, that having to confront the personal stigma associated with depression is a significant barrier to seeking professional help, with less value being placed on such support as a result (Coppens et al., 2013). Similarly, O'Connor, Martin et al. (2014) have found that social support, extraversion and perceived benefits significantly predict help-seeking behaviour in young people. Thereby, the utility of the PUDQ as a measure of MHL for depression needs to be understood and further explored within the context of such a multivariate framework.

\section{Implications, limitations and future directions}

As a multidimensional measure of MHL for depression, the PUDQ has the potential to be a useful tool in the delivery and assessment of strategies for promoting understanding of depression and alleviating susceptibility to it. For example, the PUDQ could be used by primary care workers and general practitioners in the course of raising awareness in risk groups, such as socially isolated men, who may benefit from additional psycho-education. The PUDQ offers the possibility of an easy-to-complete screening tool to identify such individuals proactively and to assess the effectiveness of interventions such as the 'Real Men, Real Depression' campaign in north America as found by Rochlen, Whilde, and Hoyer (2005) to be successful in increasing men's understanding of depression. However, the PUDQ also offers the possibility of knowing in greater detail what specific elements of MHL for depression are changing as a response to programmes. So, whilst in Australia, the 'Beyond Blue' nationwide MHL programme helped improve the recognition of depression in the population as a whole over an 8-year period (Jorm, Christensen, \& Griffiths, 2006), identification of the elements of such literacy which responded to this public health initiative would have allowed for further tailoring of this intervention going forward. The existence of the PUDQ offers this possibility to future studies examining the efficacy of such national campaigns.

The current study's finding that lower interdependence is related to lower knowledge and understanding of depression suggests that further studies using the PUDQ might examine how elements of MHL for depression are affected by programmes which enhance social support and network development. Research has found that decreasing interdependence and increasing social isolation are associated with spending more time in virtual social groups (Parks \& Roberts, 1998), particularly for those with minimally developed social networks (Shaw \& Gant, 2002), thereby implicating the need for 'in vivo' social engagement.

Further studies may also seek to investigate and extend the validity and reliability of the PUDQ in relation to additional psychological constructs and in other sampling contexts. Whilst a proportion of PUDQ subscale scores were attributable to the 
psychological and demographic variables included in this study, the existence of unexplained variance suggests other factors not incorporated here would have additional predictive utility. Identification of such factors in future studies would enhance our understanding of the concomitants of the three-dimensional model of MHL for depression reported here and would extend our comprehension of the psychometric properties associated with how it has been operationalised in the form of the PUDQ. Given the majority of the sample in this study self-designated as British, the replicability of the PUDQ subscales in other nationally and ethnically defined cultures should be examined. Though designed primarily for use at the micro-level of the individual, it is envisaged that the PUDQ can also be used to examine MHL for depression at the macro level of large social groups and could be utilised to track changes in such literacy over time (as after Dunn et al., 2009).

\section{References}

Albers, A. B., \& Biener, L. (2002). The role of smoking and rebelliousness in the development of depressive symptoms among a cohort of Massachusetts adolescents. Preventive Medicine, 34, 625-631. doi:10.1006/pmed.2002.1029

American Psychiatric Association. (2000). Diagnostic and statistical manual of mental disorders: $D S M-I V-T R$ (4th ed.). Arlington, VA: Author.

Anderson, S., \& Brownlie, J. (2011). Build it and they will come? Understanding public views of "emotions talk" and the talking therapies. British Journal of Guidance \& Counselling, 39, 53-66. doi:10.1080/03069885.2010.531385

Ang, R., Lim, K., \& Tan, A. G. (2004). Effects of gender and sex role orientation on help- seeking attitudes. Current Psychology, 23, 203-214.

Angermeyer, M., Matschinger, H., \& Riedel-Heller, S. (1999). Whom to ask for help in case of a mental disorder? Preferences of the lay public. Social Psychiatry and Psychiatric Epidemiology, 34, 202-210.

Boddington, E. L., \& McDermott, M. R. (2013). Predicting resistance to health education messages for cannabis use: The role of rebelliousness, autic mastery, health value and ethnicity. Journal of Health Psychology, 18, 157-166. doi:10.1177/1359105312438111

Brown, K., \& Ryan, R. (2003). The benefits of being present: Mindfulness and its role in psychological well-being. Journal of Personality, Social Psychology, 84, 822-848.

Cash, T. F., Kehr, J., \& Salzbach, R. F. (1978). Help-seeking attitudes and perceptions of counselor behavior. Journal of Counseling Psychology, 25, 264-269. doi:10.1037/00220167.25 .4 .264

Cattell, R. B. (1966). The scree test for the number of factors. Multivariate Behavioral Research, $1,245-276$.

Coppens, E., Van Audenhove, C., Scheerder, G., Arensman, E., Coffey, C., Costa, S., \& Koburger, N. (2013). Public attitudes toward depression and help- seeking in four European countries baseline survey prior to the OSPI-Europe intervention. Journal of Affective Disorders, 150, 320-329. doi: 10.1016/j.jad.2013.04.013

Dunn, K. I., Goldney, R. D., Grande, E., \& Taylor, A. (2009). Quantification and examination of depression- related mental health literacy. Journal of Evaluation in Clinical Practice, 15, 650-653. doi:10.1111/j.1365-2753.2008.01067.x

Farrer, L., Leach, L., Griffiths, K., Christensen, H., \& Jorm, A. (2008). Age differences in mental health literacy. BMC Public Health, 8, 125, 1-8. doi:10.1186/1471-2458-8-125

Furnham, A., Cook, R., Martin, N., \& Batey, M. (2011). Mental health literacy among university students. Journal of Public Mental Health, 10, 198-210. doi:10.1108/17465721111188223

Furnham, A., \& McDermott, M. R. (1994). Lay beliefs about the efficacy of self-reliance, seeking help and external control as strategies for overcoming obesity, drug addiction, marital problems, stuttering and insomnia. Psychology and Health, 9, 397-406.

Gilbody, S., Richards, D., Brealey, S., \& Hewitt, C. (2007). Screening for depression in medical settings with the patient health questionnaire (PHQ): A diagnostic meta-analysis. Journal of General Internal Medicine, 22, 1596-1602. 
Goldberg, D. P., \& Hillier, V. F. (1979). A scaled version of the general health questionnaire. Psychological Medicine, 9, 139-145.

Goldney, R. D., Dunn, K. I., Grande, E., Crabb, S., \& Taylor, A. (2009). Tracking depressionrelated mental health literacy across South Australia: A decade of change. Australian and New Zealand Journal of Psychiatry, 43, 476-483. doi:10.1080/00048670902817729

Griffiths, K., Christensen, H., Jorm, A., Evans, K., \& Groves, C. (2004). Effect of web-based depression literacy and cognitive-behavioural therapy interventions on stigmatising attitudes to depression: Randomised controlled trial. The British Journal of Psychiatry, 185, 342-349.

Gulliver, A., Griffiths, K. M., Christensen, H., \& Brewer, J. L. (2010). Perceived barriers and facilitators to mental health help- seeking in young people: A systematic review. $B M C$ Psychiatry, 10(113), 1-9. doi:10.1186/1471-244X-10-113

Gulliver, A., Griffiths K. M., Christensen, H., \& Brewer J. L. (2012). A systematic review of help- seeking interventions for depression, anxiety and general psychological distress. $B M C$ Psychiatry, 12(81), 1-12. doi:10.1186/1471-244X-12-81

Hawton, K., \& van Heeringen, K. (2009). Suicide. The Lancet, 373, 1372-1381. doi:10.1016/ S0140-6736(09)60372-X

The Health \& Social Care Information Centre. (2008). In-patient formally detained in hospitals under the mental health act 1983 and other legislation, England: 1997-98 to 2007-08. Leeds: NHS Information Centre. Retrieved from http://www.hscic.gov.uk/pubs.

Community and Mental Health Team, The Health and Social Care Information Centre. (2014). Quarterly improving access to psychological therapies data set reports, England - Final Q2 2014-15 summary statistics and related information, experimental statistics: Pre-release access list. Retrieved from http://www.hscic.gov.uk/pubs

Jorm, A. F. (2012). Mental health literacy: Empowering the community to take action for better mental health. American Psychologist, 67, 231-243. doi:10.1037/a0025957

Jorm, A. F. (2012). Mental health literacy. American Psychologist, 67, 231-243. doi:10.1037/ a0025957

Jorm, A. F., Blewitt, K., Griffiths, K., Kitchener, B. A., \& Parslow, R. (2005). Mental health first aid responses of the public: Results from an Australian national survey. BMC Psychiatry, 5 (9), 1-9. doi:10.1186/1471-244X-5-9

Jorm, A. F., Christensen, H., \& Griffiths, K. M. (2006). The public's ability to recognize mental disorders and their beliefs about treatment: Changes in Australia over 8 years. Australian and New Zealand Journal of Psychiatry, 40, 36-41. doi:10.1111/j.1440-1614.2006.01738.x

Jorm, A. F., Korten, A., Jacomb, P., Christensen, H., Rodgers, B., \& Pollitt, P. (1997). Mental health literacy: A survey of the public's ability to recognise mental disorders and their beliefs about the effectiveness of treatment. Medical Journal of Australia, 166, 182-186.

Jorm, A. F., \& Wright, A. (2007). Beliefs of young people and their parents about the effectiveness of interventions for mental disorders. Australian and New Zealand Journal of Psychiatry, 41, 656-666.

Klabbers, G., Bosma, H., van den Akker, M., van Boxtel, M. P. J., Kempen, G. I. J. M., McDermott, M. R., \& Van Eijk, J. T. M. (2009). Measuring rebelliousness and predicting health behaviour and outcomes: An investigation of the construct validity of the social reactivity scale. Journal of Health Psychology, 14, 771-779. doi:10.1177/1359105309338894

Kroenke, K., Spitzer, R., \& Williams, J. (2001). The PHQ- 9 - validity of a brief depression severity measure. Journal of General Internal Medicine, 16, 606-613.

Lam, B. (2005). Self- construal and depression among Vietnamese-American adolescents. International Journal of Intercultural Relations, 29, 239-250. doi:10.1016/j.ijintrel.2005.05.007

Lun, J., Kesebir, S., \& Oishi, S. (2008). On feeling understood and feeling well: The role of interdependence. Journal of Research in Personality, 42, 1623-1628.

Loureiro, L. M., Jorm, A. F., Mendes, A. C., Santos, J. C., Ferreira, R. O., \& Pedreiro, A. T. (2013). Mental health literacy about depression: A survey of portuguese youth. BMC Psychiatry, 13, 129-137.

Mackenzie, C. S., Gekoski, W., \& Knox, V. (2006). Age, gender, and the underutilization of mental health services: The influence of help- seeking attitudes. Aging \& Mental Health, 10, 574-582. doi:10.1080/13607860600641200

MacKillop, J., \& Anderson, E. (2007). Further psychometric validation of the mindful attention awareness scale (MAAS). Journal of Psychopathology and Behavioral Assessment, 29, 289-293. 
Markus, H. R., \& Kitayama, S. (1991). Culture and the self: Implications for cognition, emotion, and motivation. Psychological Review, 98, 224-253. doi:10.1037/0033-295X.98.2.224

Martins, A., Ramalho, N., \& Morin, E. (2010). A comprehensive meta-analysis of the relationship between emotional intelligence and health. Personality and Individual Differences, 49, 554-564.

Masuda, A., Suzumura, K., Beauchamp, K., Howells, G., \& Clay, C. (2005). United States and Japanese college students' attitudes toward seeking professional psychological help. International Journal of Psychology, 40, 303-313. doi:10.1080/00207590444000339

McDermott, M. R. (1987). Rebelliousness in adolescence and young adulthood (Unpublished doctoral dissertation). University College, University of Wales, Cardiff, Wales.

McDermott, M. R., \& Apter, M. J. (1988). The negativism dominance (social reactivity) scale. In M. J. Apter, J. H. Kerr, \& M. P. Cowles (Eds.), Progress in reversal theory (pp. 373-376). Amsterdam: North Holland.

McManus, S., Meltzer, H., Brugha, T., Bettington, P. \& Jenkins, R. (2009). Adult psychiatric morbidity in England - 2007, Results of a household survey. London: The Health \& Social Care Information Centre.

National Institute for Health and Care Excellence. (2009). Depression: The treatment and management of depression in adults (update). Received from http://www.nice.org.uk/CG090

O'Connor, M., Casey, L., \& Clough, B. (2014). Measuring mental health literacy - A review of scale- based measures. Journal of Mental Health, 23, 197-204.

O’Connor, P. J., Martin, B., Weeks, C. S., \& Ong, L. (2014). Factors that influence young people's mental health help-seeking behaviour: A study based on the health belief model. Journal of Advanced Nursing, 70, 2577-2587. doi:10.1111/jan.12423

Oluyinka, O. (2011). Psychological predictors of attitude towards seeking professional psychological help in a Nigerian university student population. South African Journal of Psychology, $41,310-327$.

Parks, M., \& Roberts, L. (1998). 'Making MOOsic': The development of personal relationships on line and a comparison to their off-line counterparts. Journal of Social and Personal Relationships, 15, 517-537.

Pevalin, D., \& Rose, D. (2003). Social capital for health: Investigating the link between social capital and health using the British household panel survey. London: Health Development Agency.

Reavley, N. J., Morgan, A. J., \& Jorm, A. F. (2014). Development of scales to assess mental health literacy relating to recognition of and interventions for depression, anxiety disorders and schizophrenia/psychosis. Australian \& New Zealand Journal of Psychiatry, 48, 61-69. doi: $10.1177 / 0004867413491157$

Rickwood, D., Deane, F., Wilson, C., \& Ciarrochi, J. (2005). Young people's help-seeking for mental health problems. Advances in Mental Health, 4, 218-251.

Rochlen, A. B., Whilde, M. R., \& Hoyer, W. D. (2005). The real men. Real depression campaign: Overview, theoretical implications, and research considerations. Psychology of Men \& Masculinity, 6, 186-194. doi:10.1037/1524-9220.6.3.186

Schutte, N., Malouff, J., Hall, L., Haggerty, D., Cooper, J., Golden, C., \& Dornheim, L. (1998). Development and validation of a measure of emotional intelligence. Personality and Individual Differences, 25, 167-177.

Seligman, M. E. P. (1973). Fall into helplessness. Psychology Today, 7, 43-48.

Shaw, L. H., \& Gant, L. (2002). In defense of the internet: The relationship between internet communication and depression, loneliness, self-esteem, and perceived social support. Cyberpsychology \& Behavior, 5, 157-171.

Singelis, T. (1994). The measurement of independent and interdependent self-construals. Personality and Social Psychology Bulletin, 20, 580-591.

Swami, V. (2012). Mental health literacy of depression: Gender differences and attitudinal antecedents in a representative British sample. PLoS One, 7(11), 1-6. doi:10.1371/journal.pone.0049779

Swami, V., Papanicolaou, A., \& Furnham, A. (2011). Examining mental health literacy and its correlates using the overclaiming technique. British Journal of Psychology, 102, 662-675. doi:10.1111/j.2044-8295.2011.02036.x

Tata, S. P., \& Leong, F. T. L. (1994). Individualism-collectivism, social-network orientation, and acculturation as predictors of attitudes toward seeking professional psychological help among 
Chinese Americans. Journal of Counseling Psychology, 41, 280-287. doi:10.1037/00220167.41.3.280

Van Voorhees, B., Fogel, J., Houston, T., Cooper, L., Wang, N., \& Ford, D. (2006). Attitudes and illness factors associated with low perceived need for depression treatment among young adults. Social Psychiatry and Psychiatric Epidemiology, 41, 746-754.

Wittkampf, K. A., Naeije, L., Schene, A. H., Huyser, J., \& van Weert, H. C. (2007). Diagnostic accuracy of the mood module of the patient health questionnaire: A systematic review. General Hospital Psychiatry, 29, 388-395. doi:10.1016/j.genhosppsych.2007.06.004

Wright, A., Jorm, T., Harris, M., \& McGorry, P. (2007). What's in a name? Is accurate recognition and labelling of mental disorders by young people associated with better help-seeking and treatment preferences? Social Psychiatry \& Psychiatric Epidemiology, 42, 244-250.

Yeh, C. J. (2002). Taiwanese students' gender, age, interdependent and independent selfconstrual, and collective self-esteem as predictors of professional psychological help-seeking attitudes. Cultural Diversity and Ethnic Minority Psychology, 8, 19-29. doi:10.1037/10999809.8.1.19 